\title{
Mobility and Lithic Economy in the Terminal Pleistocene of Central Honshu
}

\author{
$\boldsymbol{\Delta} \cdot \mathbf{\Delta} \cdot \boldsymbol{\Delta}$ \\ KATSUHIRO SANO
}

\section{INTRODUCTION}

The origin AND SPREAd of Microblade technology in Northern Asia and North America has become more visible based on results of recent studies (Kuzmin et al. 2007). Discussions of the global tendency toward microlithization at the end of the Pleistocene (Elston and Kuhn 2002) have provided a better understanding of this phenomenon and showed the advantages of microlithic assemblages in cases of high levels of residential mobility (Goebel 2002) and in terms of reliability and maintainability (Bleed 2002). Microblade technology, however, disappeared and was replaced by bifacial point and bifacial-stemmed point assemblages in the Japanese Islands during the Terminal Pleistocene.

Both the bifacial point and bifacial-stemmed point industries indicate different strategies of lithic raw material utilization from those of microblade industries. Longdistance transport of high-quality raw materials and economical lithic reduction employed in the microblade industries gradually changed in the bifacial point industries, and faded away in the bifacial-stemmed point industries. This article presents the transformation processes of lithic raw material utilization and of human mobility during the Terminal Pleistocene in central Honshu (Fig. 1) and discusses the related subsistence strategies.

\section{CHRONOLOGICAL FRAMEWORK}

The archaeological remains during the Terminal Pleistocene on which I concentrate are characterised by a chronological sequence comprising microblade industries (Fig. 2), bifacial point industries (Fig. 3), and bifacial-stemmed point industries (Fig. 4). These industries are defined primarily on the basis of the techno-typological aspects of assemblages. Additionally, the bifacial point industries sometimes contain undecorated pottery (Fig. 3: 6,7), and the bifacial-stemmed point industries are often associated with linear-relief pottery (Fig. 4: 6).

Both the As-YP Tephra and As-K Tephra, which are attributed to the same eruptive event, show a set of radiocarbon dates (Nakamura et al. 1997) calibrated to be beJapan 


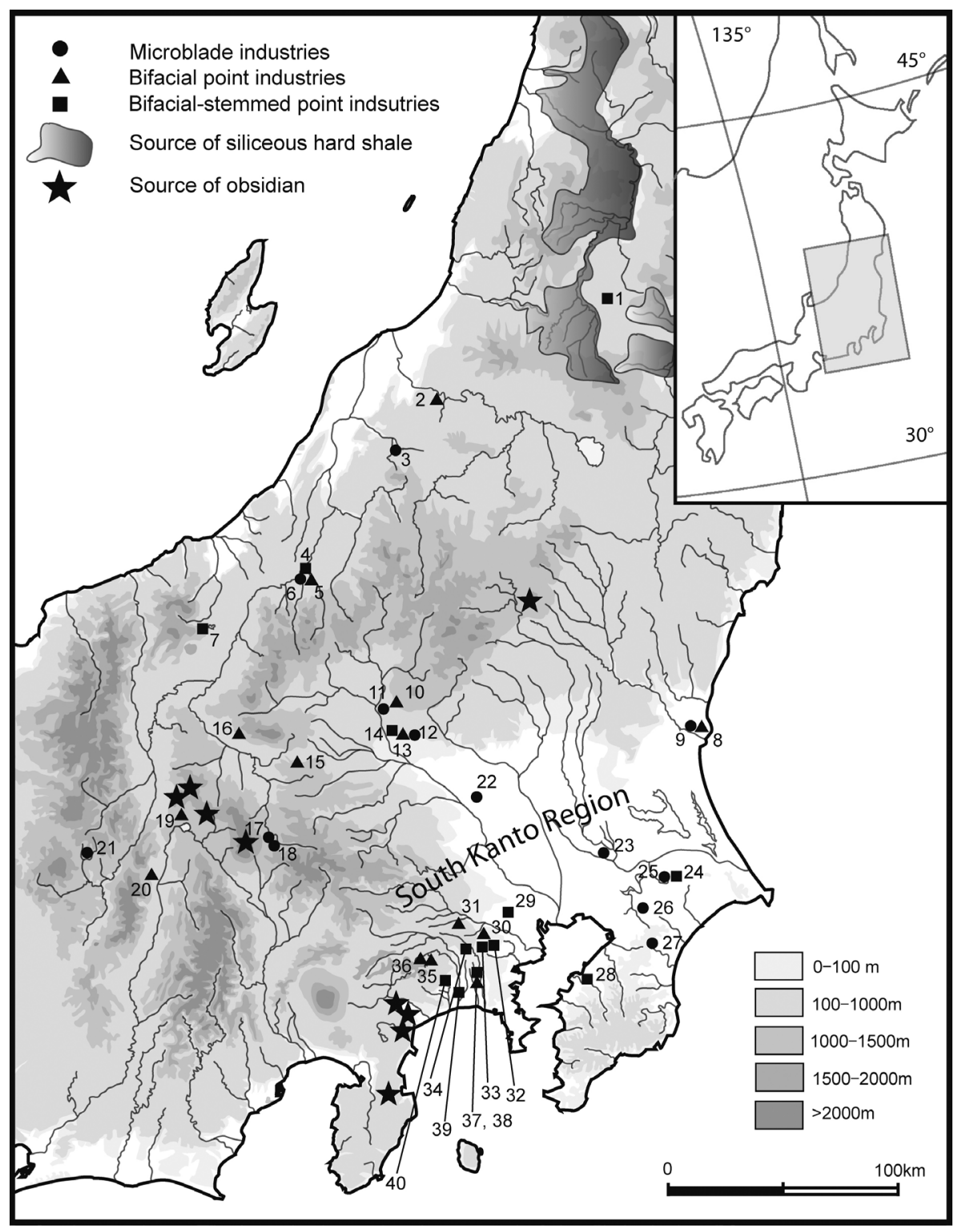

Fig. 1. Topographic map showing location of sites in the Terminal Pleistocene in central Honshu (after Sano 2006). Microblade industries: 3: Nakatsuchi; 6: Shomen-Nakajima (M); 9: Ushirono B; 11: Uenohara; 12: Kashiranashi; 17: Nakappara 5B; 18: Nakappara 1G; 21:Yanagimata A; 22: Shirakusa; 23: Kashiwahara; 25: Airport No. 61; 26: Kidoba; 27: Oami-Yamadadai No. 8. Bifacial point industries: 2: Uenotaira C; 5: Shomen-Nakajima (B); 8: Ushirono A; 10: Bogaito; 13: Aratokita-Sankido; 15: Happusan VI; 16: Karasawa B; 19: Nakajima B; 20: Mikoshiba; 30: TNT No. 27; 31: TNT No. 426; 35: Kitahara (No. 10/11 North); 36: Minami (No. 2); 37: Yoshioka Site Group A. Bifacial-stemmed point industries: 1: Hinata caves; 4: Motonoki; 7: Seiko-Sanso B; 14: Kojimada-Yokaichi; 24: Airport No. 12; 28: Sannodai; 29: Mukainohara B; 32: Hanamiyama; 33: Miyanomae; 34: Miyagase Site Group; 38: Yoshioka Site Group C; 39: Keio SFC; 40: Sannomiya-Shimoyato. 

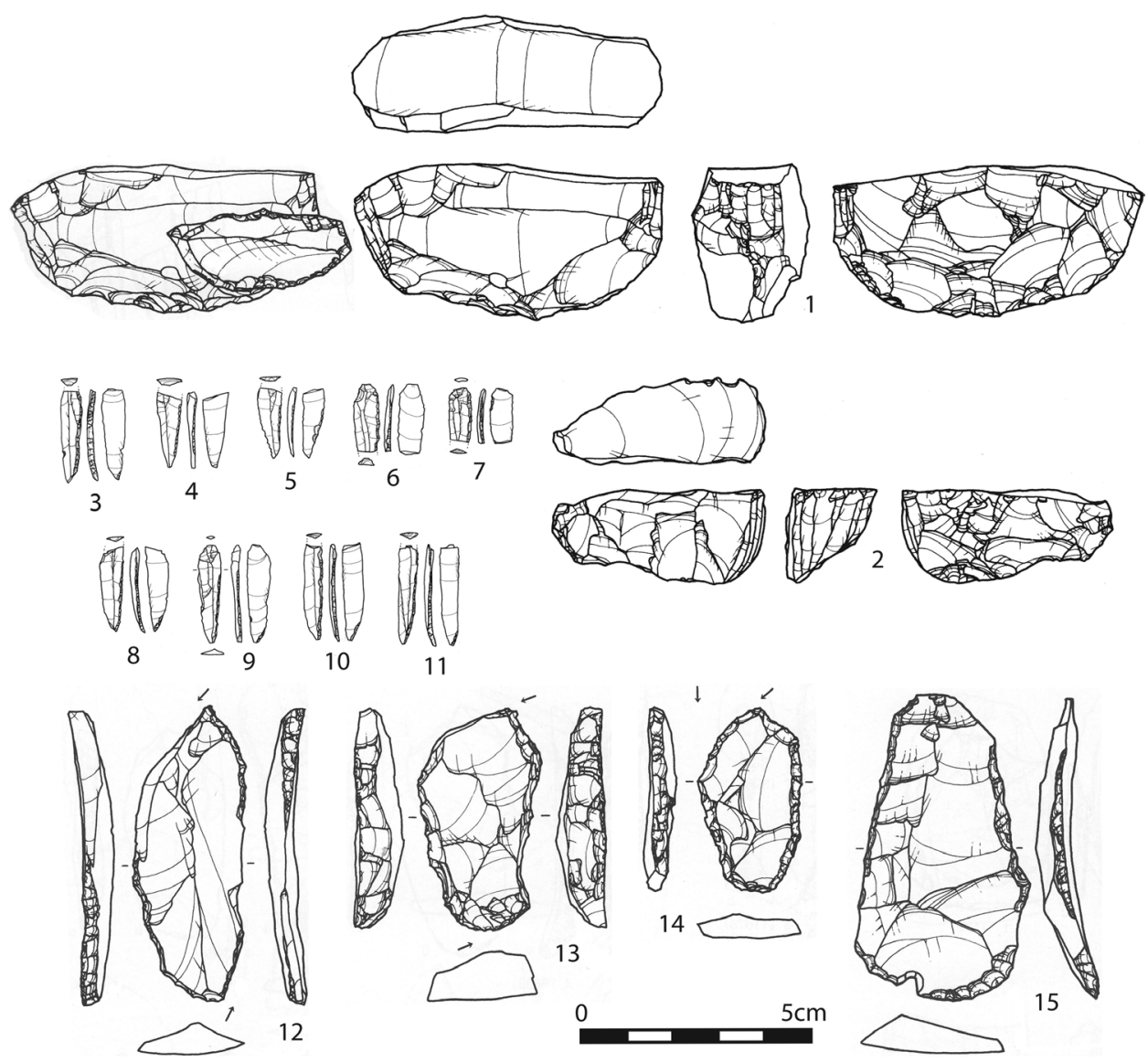

Fig. 2. Artifacts from the microblade industries at Araya site (Serizawa and Suto 2003). 1: microblade core refitted with a burin; 2: microblade core; 3-11: microblades; 12-14: burins; 15: end scraper.

tween c. 17,000 and c. 16,000 B.P. based on the CalPal-2007 ${ }_{\text {Hulu }}$ (www.calpal.de) (all subsequent dates are calibrated based on the CalPal-2007 $\left.{ }_{\text {Hulu }}\right)$. The microblade industries were recovered not only from the layer under the As-YP/K Tephra, but also from within it; the bifacial point industries were discovered in the As-YP/K Tephra layer and also above it; and the bifacial-stemmed point industries were encountered in the layer covering the As-YP/K Tephra (Fig. 5). All the industries were unearthed from the layer under the $\mathrm{As}-\mathrm{Sj}$ Tephra at c. 13,500-13,000 B.P. (Nakamura et al. 1997).

The tephra chronology mentioned above and the radiocarbon dates (Kudo 2005; Ono et al. 2002) show that modern humans who retained microblade industries with wedge-shaped microblade cores applied by theYubetsu method (Nakazawa et al. 2005) were living in central Honshu between c. 18,000 and 16,000 B.P. Subsequently, between c. 17,000 and c. 16,000 B.P. bifacial point industries emerged. These gave way gradually to the bifacial-stemmed point industries at around 15,000 B.P. Although a stratigraphic analysis has revealed that the microblade industries including subconical cores emerged somewhat earlier than the wedge-shaped microblade core assemblages, 

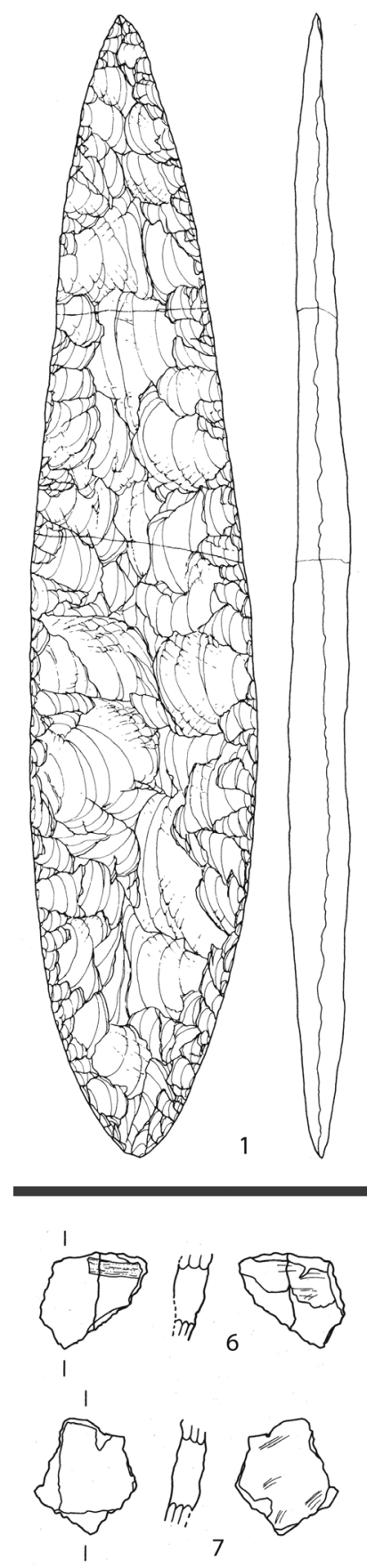
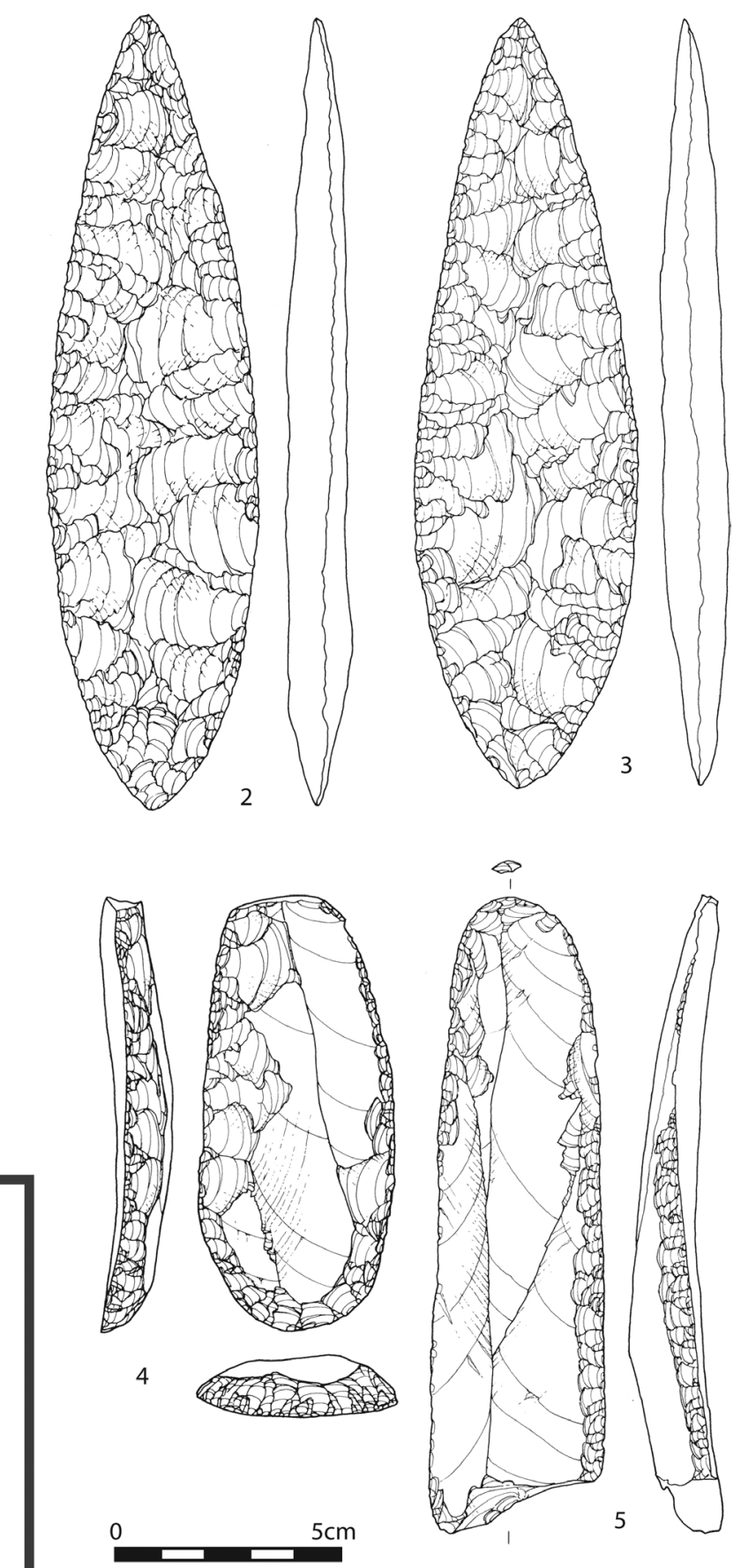

Fig. 3. Artifacts from the bifacial point industiries. 1-5: Mikohshiba site (Hayashi and Kami-Ina Archaeological Society 2008); 6, 7: Kitahara (No. 10/11 North) site (Kanagawa Archaeology Foundation 1998b). 1-3: bifacial points; 4: end scraper; 5 : side scraper; 6,7 : fragments of pottery. 

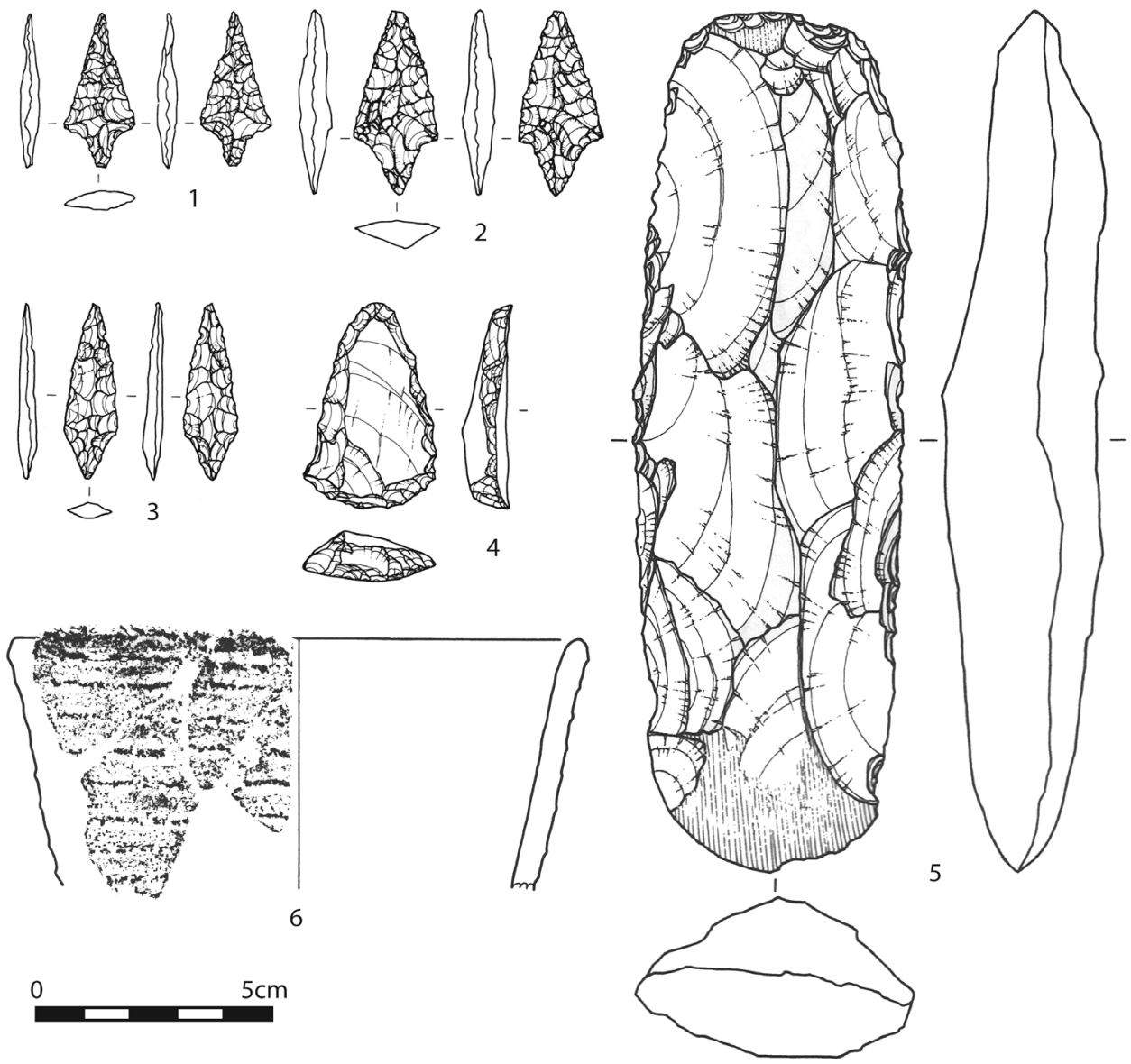

Fig. 4. Artifacts from the bifacial-stemmed point industries at Seiko-Sanso B site (Nagano Prefecture Archaeological Research Centre 2000). 1-3: bifacial-stemmed points; 4: end scraper; 5: edge-ground axe; 6: linear-relief pottery.

there are no reliable radiocarbon dates associated with subconical microblade cores so far. Because the timing of emergence of the subconical microblade cores is still in dispute, this article focuses on the wedge-shaped microblade assemblages.

\section{LITHIC RAW MATERIAL UTILIZATION STRATEGIES}

A comparison of the distribution of lithic raw material sources reveals distinct features among these industries. The hunter-gatherers responsible for the microblade industries equipped themselves with high-quality raw materials, especially the wedge-shaped microblade cores that were predominantly made on high-quality materials such as the siliceous hard shale present in northern Honshu (Hata 1998) (Fig. 1). The ratio of siliceous hard shale in lithic raw material assemblages remained high even though this material had to be carried over distances of more than $200 \mathrm{~km}$ (Fig. 6) (Sano 2006, 2007). People used siliceous hard shale exclusively for producing tools, comprising 


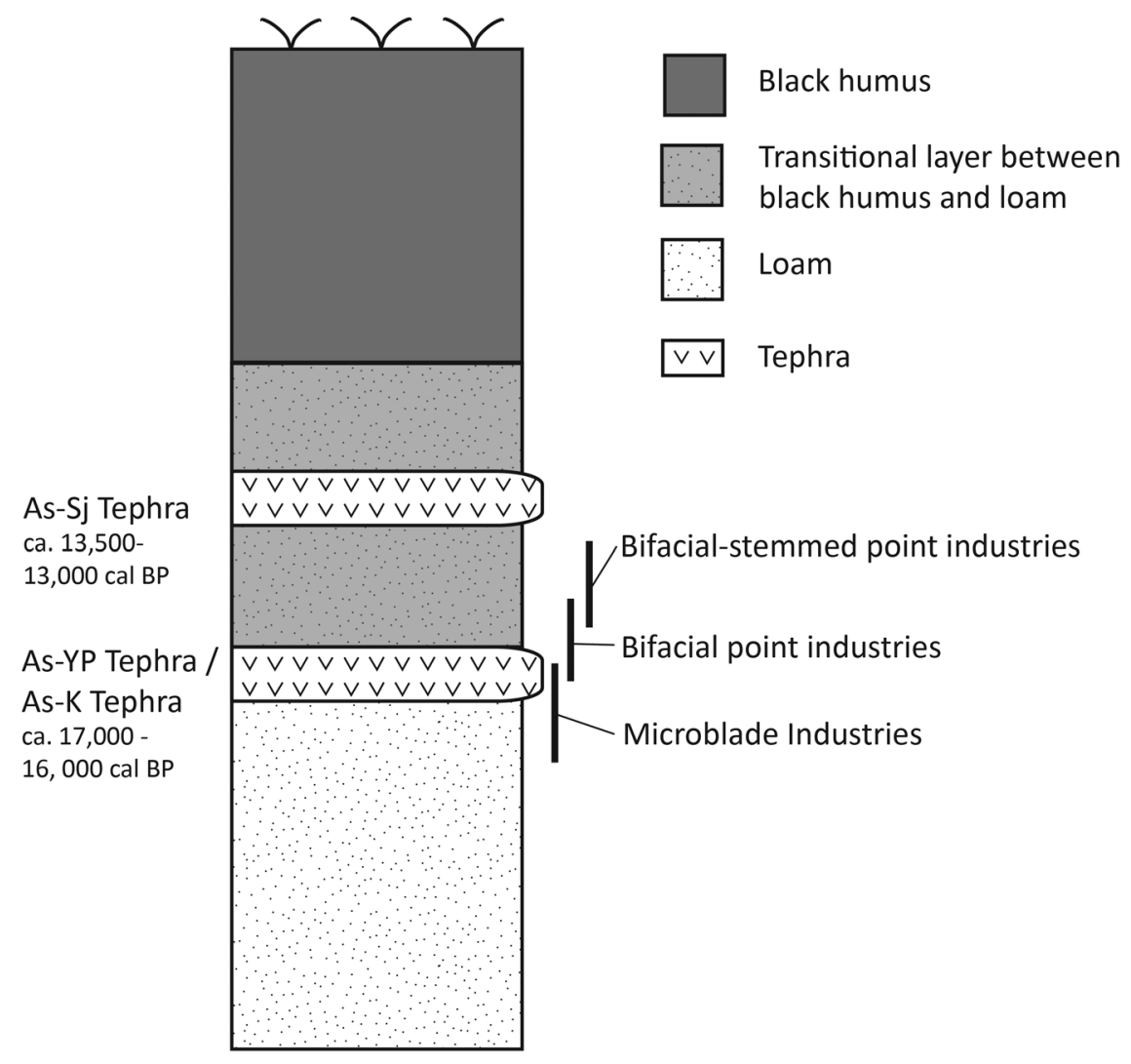

Fig. 5. Schematic stratigraphic column showing the relation of key tephra to vertical range recovering microblade industries, bifacial point industries, and bifacial-stemmed point industries.

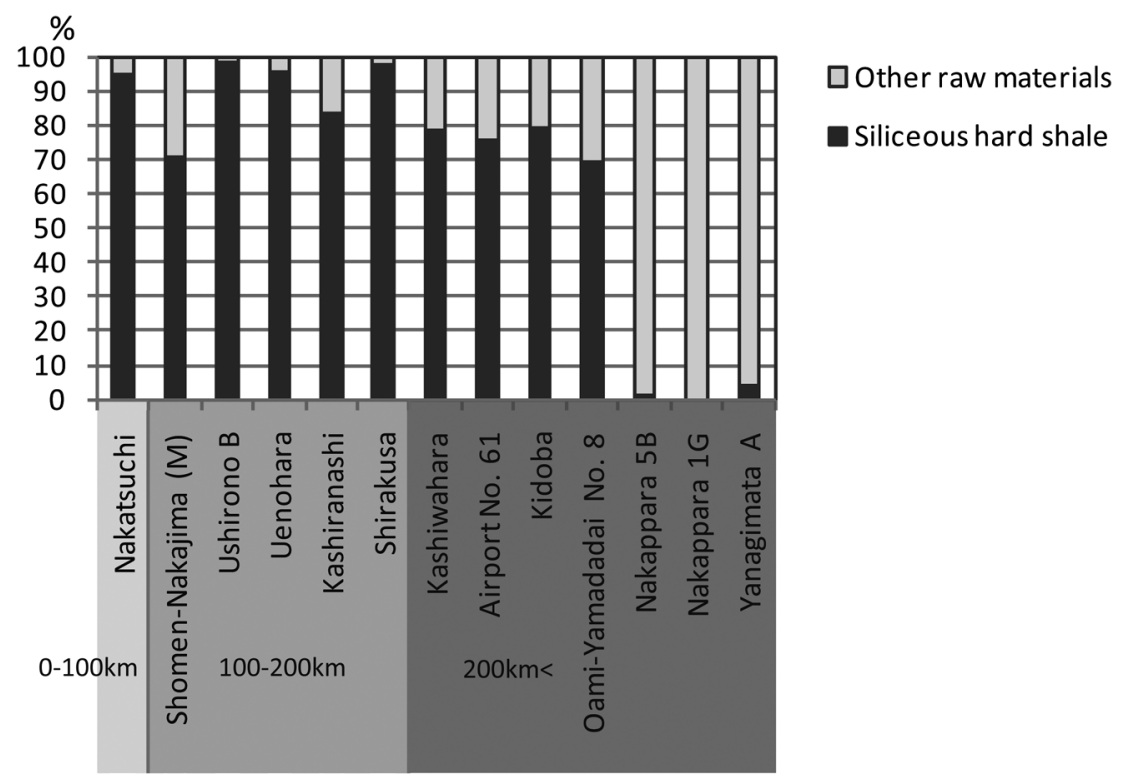

Fig. 6. Comparison between ratio of siliceous hard shale and other raw materials in conjunction with distance from sites to the source of siliceous hard shale in microblade industries. 


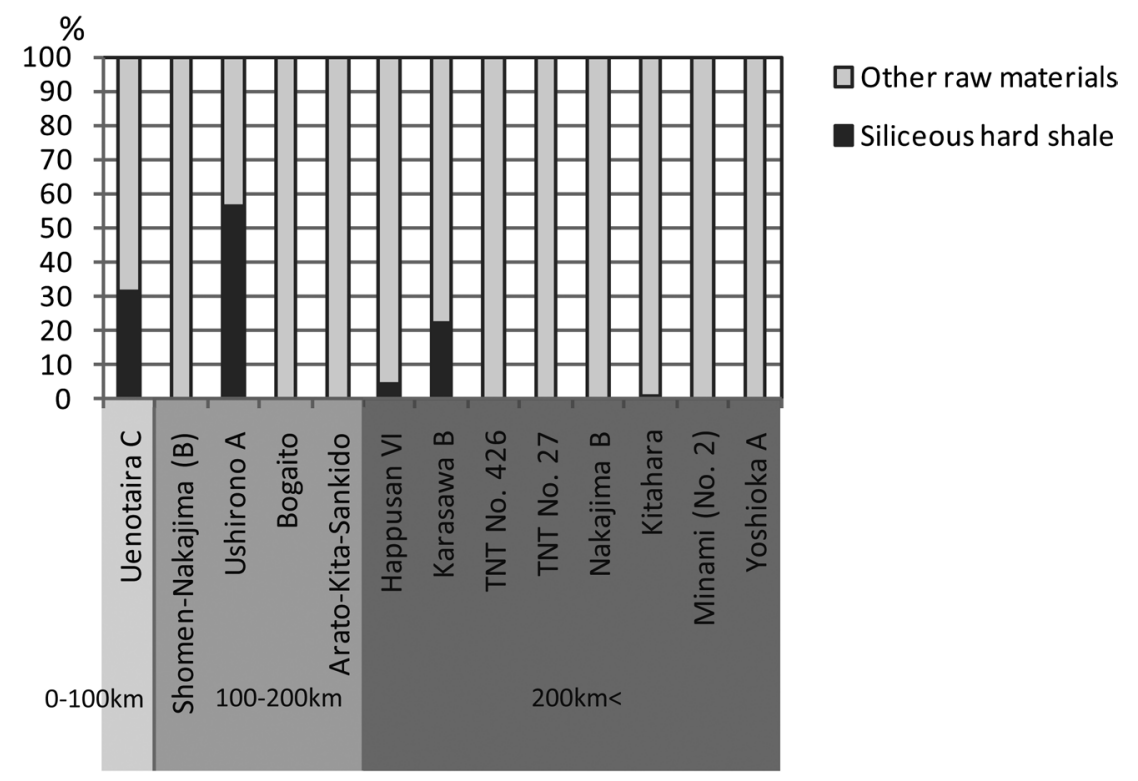

Fig. 7. Comparison between ratio of siliceous hard shale and other raw materials in conjunction with distance from sites to the source of siliceous hard shale in bifacial point industries.

microblades, burins, end scrapers and borers, and occasionally they also acquired local raw materials for preparing pebble tools or supplying additional tools.

Although in the bifacial point industries high-quality raw materials, such as siliceous hard shale and obsidian, were also transported over distances of $100 \mathrm{~km}$ (Sato and Tsutsumi 2007), long-distance transport of siliceous hard shale no longer occurred regularly, and the proportion of high-quality materials on sites located at a distance greater than $100 \mathrm{~km}$ from the source is not as high as that of the microblade industries (Fig. 7). The high-quality raw materials were brought onto sites from distant sources in the form of prepared cores, blanks and tools. Nevertheless, most lithic tools were prepared from abundant local raw materials, such as shale, cherts, silisified tuff, and andesite (Shibata 1995; Tamura et al. 2003, 2004; Tamura and Kunitake 2006).

In the bifacial-stemmed point industries, raw material composition is dominated by local materials derived from diverse origins (Sano 2006). A small amount of highquality non-local materials was transported to sites from more distant sources; however, modern humans associated with the bifacial-stemmed point industries were not dependent on high-quality materials. Only small quantities of siliceous hard shale were carried over distances of c. $100 \mathrm{~km}$ (Fig. 8).

The variability of lithic raw materials also reveals differences of lithic raw material acquisition strategies among these industries. While the microblade industries have provided evidence of the usage of an average of around five different types of raw material, the bifacial point industries and bifacial-stemmed point industries have so far yielded approximately eight different types on average (Fig. 9). The difference in raw material utilization among three industries is clearly observed at sites in the south Kanto region, which is far from the source of siliceous hard shale (Tables 1-3). In the microblade industries, the siliceous hard shale was almost exclusively utilized for for- 


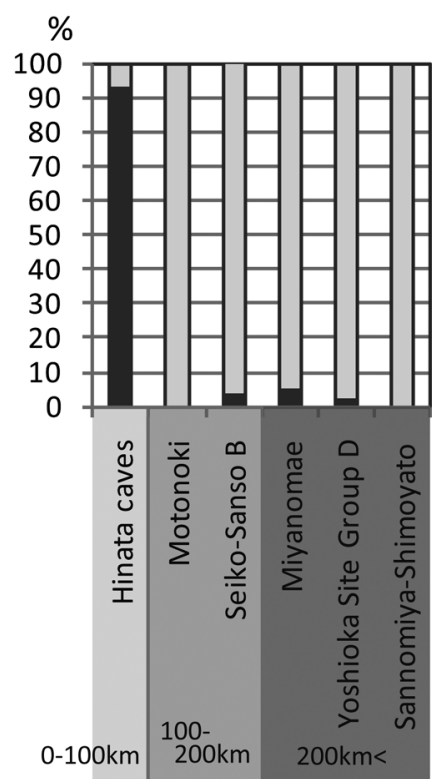

No.

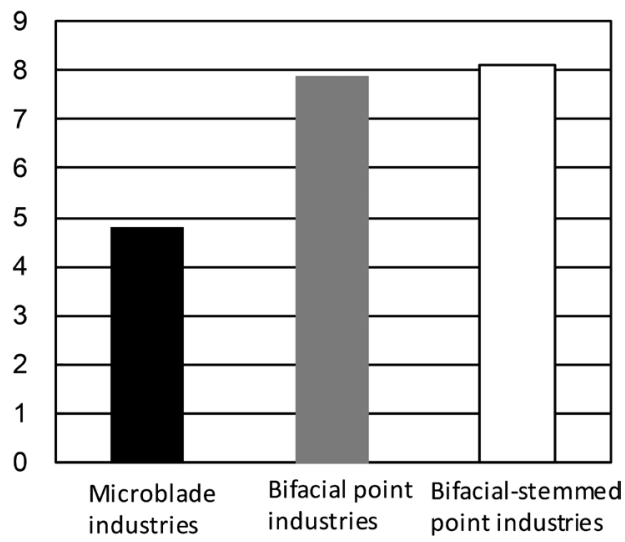

Fig. 8. Comparison between ratio of siliceous hard shale and other raw materials in conjunction with distance from sites to the source of siliceous hard shale in bifacial-stemmed industries.
Fig. 9. The number of different types of raw material in the microblade industries, bifacial point industries, and bifacial-stemmed point industries (on average).

mal tools, and the total number of other raw materials constitutes less than 30 percent of the assemblage. Those hunter-gatherers associated with microblades only rarely exploited local materials around sites; on the other hand, the groups responsible for bifacial points and bifacial-stemmed points relied on a diversity of local materials and had no preference for high-quality materials.

\section{REDUCTION SEQUENCES}

In the microblade industries, knappers prepared bifacial blanks to serve as wedgeshaped microblade cores from which they produced deliberately elongated flakes (Fig. 2: 1). These blade-like flakes were modified by retouch into a variety of tools. Subse- 
Table i. Composition of Lithic Raw Materials in Microblade Industries at Kashiwahara Site and Airport No. 6i Site in South Kanto Region.

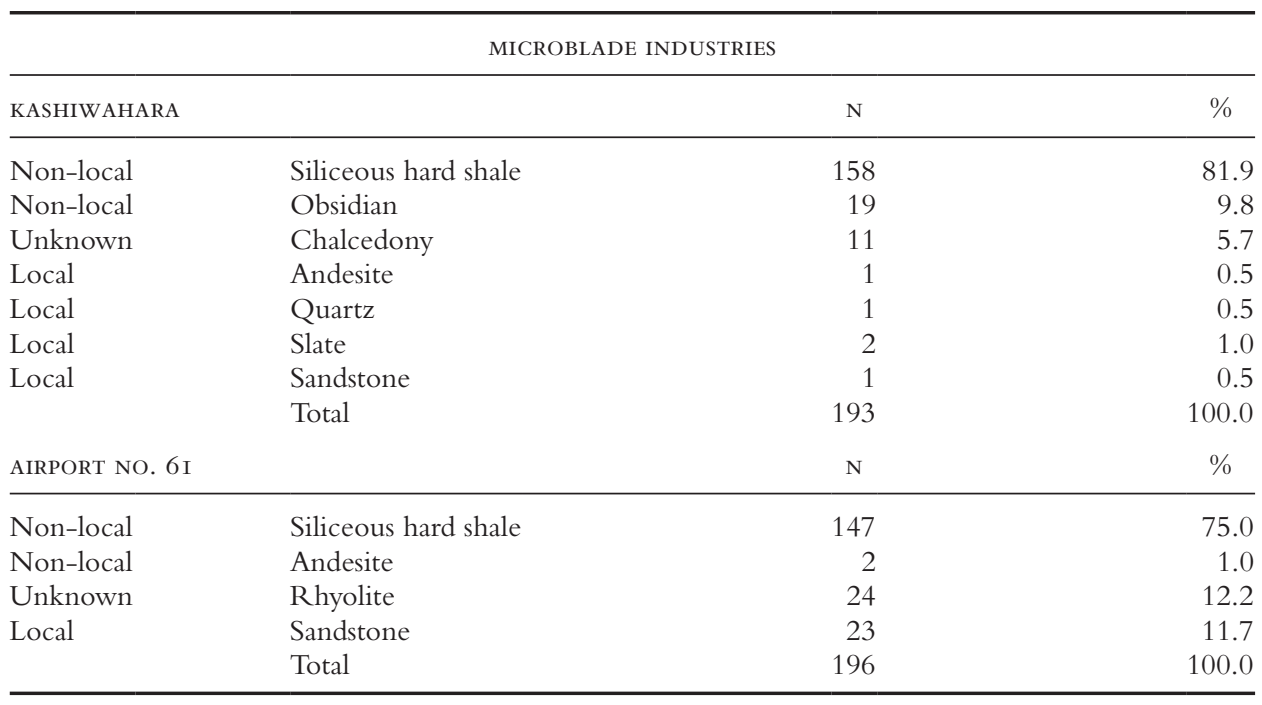

Table 2. Composition of Lithic Raw Materials in Bifacial Point Industries at TNT No. 27 Site and Kitahara (No. io/i i North) Site in South Kanto Region.

\begin{tabular}{llrr}
\hline & & BIFACIAL POINT INDUSTRIES & \\
\hline TNT NO. 27 & & $\mathrm{N}$ & $\%$ \\
\hline Non-local & Obsidian & 50 & 2.5 \\
Local & Shale & 1104 & 55.0 \\
Local & Chert & 345 & 17.2 \\
Local & Silicified tuff & 152 & 7.6 \\
Local & Andesite & 11 & 0.5 \\
Local & Hornfels & 316 & 15.7 \\
Local & Slate & 24 & 1.2 \\
Local & Sandstone & 5 & 0.2 \\
& Total & 2007 & 100.0 \\
KITAHARA (NO. IO $/$ I I & NorTH) & $\mathrm{N}$ & $\%$ \\
\hline Non-local & Siliceous hard shale & 8 & 0.9 \\
Non-local & Obsidian & 105 & 11.9 \\
Local & Shale & 1 & 0.1 \\
Local & Chert & 6 & 0.7 \\
Local & Silicified tuff & 296 & 33.4 \\
Local & Andesite & 463 & 52.3 \\
Local & Hornfels & 3 & 0.3 \\
Unknown & Diabase & 4 & 0.5 \\
& Total & 886 & 100.0 \\
\hline
\end{tabular}

quently, a platform was formed upon one of the lateral edges of the bifacial blanks by removing spalls, and finally microblades were detached parallel to the minor axis. The knappers rejuvenated and reshaped microblade cores to allow for the continual production of microblades; the flakes produced in the course of this process were some- 
Table 3. Composition of Lithic Raw Materials in Bifacial-stemmed Point Industries at Yoshioka Site and Sannomiya-Shimoyato Site in South Kanto Region.

\begin{tabular}{|c|c|c|c|}
\hline \multicolumn{4}{|c|}{ BIFACIAL-STEMMED POINT INDUSTRIES } \\
\hline \multicolumn{2}{|c|}{ YOSHIOKA SITE GROUP C } & \multirow{2}{*}{$\begin{array}{l}\mathrm{N} \\
8\end{array}$} & \multirow{2}{*}{$\begin{array}{l}\% \\
1.1\end{array}$} \\
\hline Non-local & Siliceous hard shale & & \\
\hline Non-local & Obsidian & 6 & 0.8 \\
\hline Local & Shale & 50 & 6.6 \\
\hline Local & Chert & 197 & 26.1 \\
\hline Local & Silicified tuff & 341 & 45.2 \\
\hline Local & Andesite & 48 & 6.4 \\
\hline Local & Hornfels & 101 & 13.4 \\
\hline Unknown & Rhyolite & 1 & 0.1 \\
\hline Unknown & Diorite & 2 & 0.3 \\
\hline \multirow{2}{*}{ Local } & Sandstone & 1 & 0.1 \\
\hline & Total & 755 & 100.0 \\
\hline \multicolumn{2}{|c|}{ SANNOMIYA-SHIMOYATO } & $\mathrm{N}$ & $\%$ \\
\hline Non-local & Siliceous hard shale & 12 & 0.02 \\
\hline Non-local & Obsidian & 43 & 0.08 \\
\hline Local & Shale & 54 & 0.10 \\
\hline Local & Chert & 75 & 0.14 \\
\hline Local & Jasper & 20 & 0.04 \\
\hline Local & Silicified tuff & 757 & 1.41 \\
\hline Local & Andesite & 52472 & 97.66 \\
\hline Local & Hornfels & 246 & 0.46 \\
\hline Unknown & Rhyolite & 5 & 0.01 \\
\hline Unknown & Diorite & 22 & 0.04 \\
\hline Unknown & Diabase & 10 & 0.02 \\
\hline \multirow[t]{2}{*}{ Local } & Sandstone & 14 & 0.03 \\
\hline & Total & 53730 & 100.0 \\
\hline
\end{tabular}

times also transformed into tools when appropriate. The microblade cores were then utilized until they were reduced to very small pieces. The reduction sequences employed here must be regarded as economical.

The modern humans of the microblade industries left the quarry workshops, which were located at or near sources of siliceous hard shale, with lithic artifacts such as bifacial core, microblade cores, tool blanks, and shaped-out tools. Upon their arrival at sites away from the source, bifacial cores had already been modified into microblade cores, and both the microblade cores and the tools had already been subject to extreme reduction. The lithic artifact assemblages transported from the source and the varieties of lithic raw materials present in the assemblages were always similar, independent of the distance from the respective sources; however, the total volume of lithic artifacts was found to decrease with distance from the siliceous hard shale sources owing to the fact that the microblade people acquired only scarce amounts of additional lithic raw materials in the course of their movements.

The bifacial point industries show two basic reduction sequences. One reduction strategy aimed to produce bifacial tools, such as bifacial points and edge-ground axes. The bifacial points are of a leaf-shape and often measure more than $10 \mathrm{~cm}$ in length (Fig. 3). Another strategy supplied blades which were transformed into end scrapers, 
burin-end scrapers, and side scrapers. Although considerable flakes were removed during the production of bifacial points and bifacial blanks for edge-ground axes, byproducts were certainly not exploited as frequently as in the microblade industries. Since blade cores or irregular cores provided tool blanks, by-products of the biface production were occasionally utilized, provided they were in a suitable form.

The extent of by-product exploitation is confirmed only rarely in the bifacialstemmed point industries. Lithic tools were made principally on irregular cores, and biface reduction, employed in the production of bifacial-stemmed points, provided a much lower frequency of tool blanks. The methods of tool blank production are similar to those of the Neolithic in central Honshu of the Japanese Islands, i.e., efficient strategies for producing standardized blanks no longer applied; instead, people used simple methods to obtain pieces that were then modified into the intended tools through retouch.

\section{MOBILE STRATEGIES DURING THE TERMINAL PLEISTOCENE}

Human mobility discussed here concerns (1) the distances of moves, and (2) the duration of occupation (frequency of moves). The density and diversity of artifacts and the presence of pottery, tools for plant processing, architectural remains and storage structures with occupational intensity represent reasonable indicators for the transition of mobile strategies during the Terminal Pleistocene.

Lithic raw material movement in the microblade industries suggests that people journeyed over long distances (Sano 2006, 2007). Moreover, rational and economical reduction sequences allowed them to prepare necessary tools from the siliceous hard shale they carried with them. This strategy made it possible to minimize costs for exploiting additional raw materials near the camp; therefore, the hunter-gatherers were able to move to their next destination without having to acquire any other varieties of raw materials. Small quantities of remains (Table 1) and low varieties of lithic raw materials (Fig. 9) indicate that the camps of hunter-gatherers were occupied only for a short duration and changed location frequently. Their light inventory, comprising microblades, shaped-out tools, tool blanks, and limited microblade cores, also reflects a high degree of mobility. Furthermore, with the exception of the Araya site (Serizawa and Suto 2003), there are no sites that display evidence of occupational intensity. All these factors suggest that the microblade industries were practiced by highly mobile hunter-gatherers who moved long distances within their annual cycle, and occupied sites only for short durations.

The utilization of non-local materials, such as obsidian, in the bifacial point industries indicates that the hunter-gatherers equipped with bifacial points also covered great distances. However, the distances involved do not appear to have been as extensive as those of the microblade industries known to have covered distances of more than $200 \mathrm{~km}$. The territory of human groups in the bifacial point industries might have been around $100 \mathrm{~km}$, based on lithic raw material movement. In contrast to microblade-manufacturing human groups, bifacial point-producing groups spent longer periods of time exploiting sources in the vicinity of their sites, as reflected by the large variety of recovered lithic raw material. Additionally, the presence of edgeground axes at sites Karasawa B (Morishima et al. 1998), Mikoshiba (Hayashi and Kami-Ina Archaeological Society 2008), and Yoshioka Site Group A (Kanagawa Archaeology Foundation 1998a) and the emergence of pottery at sites Kitahara (No. 
10/11 North) (Kanagawa Archaeology Foundation 1998b) and Aratokita-Sankido (Gunma Archaeology Foundation 1992) also imply that the demand for plant materials began to increase slightly in this period. The bifacial point hunter-gatherers may have moved around within limited areas over durations greater than that estimated in the microblade industries. Nevertheless, this does not mean that the inhabitants occupied just one site over a long period, as only limited indications of occupational intensity such as architectural remains, tools for plant processing, and quantities of pottery were recovered from the bifacial point sites. Therefore, the bifacial point hunter-gatherers might still have undertaken frequent moves, and annually they may have covered a relatively long distance. In comparison to the microblade industries, however, people exploited sources around the site, thus spending more time in an overall smaller territory.

It is likely that the hunter-gatherers responsible for the bifacial-stemmed point industries no longer moved great distances in an annual cycle, as exotic raw materials are always found at an advanced stage of reduction and there are no non-local materials that show core reduction or tool preparation on site. Those tools at an advanced stage of reduction might well have been produced much earlier or exchanged with other human groups. At least, there is a low probability that their annual movement included plans for the acquisition of high-quality materials at locations more than 100 $\mathrm{km}$ distant. Their annual territory was probably even smaller than that of the bifacial point industries. The density and diversity of artifacts and the increase of pottery, tools for plant processing and dwelling structures (Kanomata 2007; Kudo 2004), are all aspects that suggest these people occupied their camp for long periods of time. Whereas such associations for occupational intensity were still uncommon in the bifacial point industries, during the bifacial-stemmed point industries they became more common.

In addition to this reduction in hunter-gatherer mobility, at the transition from microblade industries to bifacial-stemmed point industries, the lithic raw material utilization strategies changed completely. The human groups who created the bifacialstemmed point industries were no longer required to handle their lithics in an economical fashion, because they now discontinued utilizing non-local high-quality materials in favor of abundant local materials. This transformation of the lithic raw material utilization strategies may have been supported by an increase in plant utilization. Exploiting more diverse sources in local areas enabled the hunter-gatherers to live within smaller territories. Thus, during the Terminal Pleistocene there is a temporal coincidence of three important factors. Firstly, the mobility of hunter-gatherers decreased; secondly, there occurred a change from rational and economical reduction sequences to expedient and wasteful strategies; and thirdly, there was an increase in the occurrence of pottery, tools for plant processing, and dwelling structures.

\section{CONCLUSION}

Reduced mobility of the Terminal Pleistocene hunter-gatherers does not mean that a sedentary settlement system based on the permanent year-round occupation now prevailed. Even the modern humans associated with the bifacial-stemmed point industries were doubtlessly nomadic hunter-gatherers. Moreover, the use of pottery and the erection of dwelling structures decreased in the succeeding colder period of the Younger Dryas. The dramatic increase in pottery production and the construction of 
stable dwellings appeared at length at c. 11,000 B.P., which correlates with the beginning of the Holocene. In this period, humans began to settle in more sedentary settlements, and made use of storage structures and shell middens. Additionally, the required annual territory was much smaller than that of the Terminal Pleistocene.

The description of the changes observed in lithic raw material utilization during the Terminal Pleistocene reveals how hunter-gatherers changed their lithic reduction strategies, adapting available lithic raw materials. The economical reduction sequences of the microblade people allowed them to prepare necessary tools from nearly exclusively siliceous hard shale and, therefore, to minimize costs for exploiting additional raw materials, which may support their highly mobile strategy. In contrast, the humans associated with the bifacial-stemmed point industries no longer prepared their lithics economically, since they utilized abundant local materials instead of transporting nonlocal high-quality materials. Furthermore, this transformation coincided temporally with the increase in plant utilization. Although the degree of plant utilization in this period must have been much lower than at the time of the Holocene hunter-gatherers, this new subsistence strategy probably reduced the necessity for the exploitation of resources distributed over extensive areas, and more diverse sources were exploited in local areas. Thus, reduced mobility during the Terminal Pleistocene implies the appearance of strategic changes in subsistence, which enabled survival within smaller territories.

\section{ACKNOWLEDGMENTS}

I thank Akira Ono and Akira Iwase for comments and discussion on this topic. This paper profited from comments by Peter Bleed on my oral presentation at the 72nd annual meeting of the Society for American Archaeology in Austin, which I appreciate. I also thank Izuho Masami for asking me to present this study at the meeting. I am grateful to Yuichiro Kudo, Yamaoka Takuya, and Yoshitaka Kanomata for their help in gathering literature and to Lee Clare for fixing my English in an earlier manuscript. Special thanks are due to Yuichi Nakazawa, who contributed efforts to edit this special issue.

\section{REFERENCES CITED}

Bleed, Peter

2002 Cheap, regular, and reliable: Implications of design variation in late Pleistocene Japanese microblade technology, in Thinking Small: Global Perspectives on Microlithization: 95-102, ed. R. G. Elston and L. S. Kuhn. Arlington: Archaeological Papers of the American Anthropological Association Number 12.

Elston, Robert G., and Steven L. Kuhn, eds.

2002 Thinking Small: Global Perspectives on Microlithization. Arlington: Archaeological Papers of the American Anthropological Association Number 12.

Goebel, Ted

2002 The "microblade adaptation" and recolonization of Siberia during the late Upper Pleistocene in Thinking Small: Global Perspectives on Microlithization: 117-131, ed. R. G. Elston, and L. S. Kuhn. Arlington: Archaeological Papers of the American Anthropological Association Number 12 .

Gunma Archaeology Foundation, ed.

1992 Arato-Kita-Sankido Site II. Kita-Tachibana: Gunma Archaeology Foundation (in Japanese).

Hata, Akishige

1998 Siliceous hard shale and its geographical distribution. Kokogaku-Journal 432:31-35 (in Japanese). 
Hayashi, Shigeki, and Kami-Ina Archaeological Society, eds.

2008 Mikoshiba Site. Nagano: Shinmai Shoseki Publication Centre (in Japanese).

Kanagawa Archaeology Foundation, ed.

1998a Yoshioka Site Group V-Yokohama: Kanagawa Archaeology Foundation (in Japanese).

1998 biyagase Site Group XV: Kitahara (No. 10/11 North) Site. Yokohama: Kanagawa Archaeology Foundation (in Japanese).

Kanomata, Yoshitaka

2007 The human adaptation to the environmental change in east Japan from the end of the Pleistocene to the beginning of the Holocene epoch. Miyagi Kokogaku 9:1-20 (in Japanese).

Kudo, Yuichiro

2004 Reconsidering the geochronological and archaeological framework of the late Pleistoceneearly Holocene transition on the Japanese Islands, in Hunters in a Changing World. Environment and Archaeology of the Pleistocene-Holocene Transition (ca. 11,000-9,000 B.C.) in Northern Central Europe. Workshop of the U.I.S.P.P. XXXII at Greifswald in September 2002. Internationale Archäologie: Arbeitsgemeinschaft, Symposium, Tagung, Kongress Band 5:253-268, ed. T. Terberger and B. V. Eriksen. Rahden/Westf: Marie Leidorf.

2005 The temporal correspondence between archaeological chronology and environmental changes in the Final Pleistocene in eastern Honshu Island. The Quaternary Research 44:5164.

Kuzmin, Yaroslav V., Susan G. Keates, and Chen Shen, eds.

2007 Origin and Spread of Microblade Technology in Northern Asia and North America. Burnaby, B.C.: Archaeology Press, Simon Fraser University.

Morishima, Minoru, Hiroshi Kasazawa, Hajime Kawakami, Tadayoshi Yaguchi, Hiroo Yajima, Nobuyuki Sato, and Takashi Tsutsumi, eds.

1998 Karasawa B Site: A Transitional Lithic Industry of the Late Palaeolithic to the Incipient Jomon. Koshoku: Institute for Cultural Studies of Ancient Chikuma Valley (in Japanese with English summary).

Nagano Prefecture Archaeological Research Centre, ed.

2000 Jyo-shin-etsu Highway Archaeological Research Report 16: Shinano Town No. 2. Nagano: Nagano Prefecture Archaeological Research Centre (in Japanese).

Nakamura, Toshio, Seichiro Tsuji, Hiroyuki Takemoto, and Akiko Ikeda

$1997{ }^{14} \mathrm{C}$ age measurements with accelerator mass spectrometry of Asama Tephra stratigraphic samples around Minami-Karuizawa, the Latest Pleistocene, Nagano Prefecture, central Japan. The Journal of Geological Society of Japan 103:990-993 (in Japanese with English abstract).

Nakazawa, Yuichi, Masami Izuho, Jun Takakura, and Satoru Yamada

2005 Toward an understanding of technological variability in microblade assemblages in Hokkaido, Japan. Asian Perspectives 44:276-292.

Ono, Akira, Hiroyuki Sato, Takashi Tsutsumi, and Yuichiro Kudo

2002 Radiocarbon dates and archaeology of the late Pleistocene in the Japanese Islands. Radiocarbon $44: 477-494$.

Sano, Katsuhiro

2006 Lithic raw material utilization in central Honshu during the Terminal Pleistocene. Current Research in the Pleistocene 23:29-30.

2007 Emergence and mobility of microblade industries in the Japanese Islands, in Origin and Spread of Microblade Technology in Northern Asia and North America: 79-90, ed. Y. V. Kuzmin, S. G. Keates, and C. Shen. Burnaby, B.C.: Archaeology Press, Simon Fraser University.

Sato, Hiroyuki, and Takashi Tsutsumi

2007 The Japanese microblade industries: Technology, raw material procurement, and adaptations, in Origin and Spread of Microblade Technology in Northern Asia and North America: 53-78, ed. Y. V. Kuzmin, S. G. Keates, and C. Shen. Burnaby, B.C.: Archaeology Press, Simon Fraser University.

Serizawa, Chosuke, and Takashi Suto, eds.

2003 The Araya Site: Report of the Second and Third Term Excavations, 1988-1989. Sendai: Department of Archaeology, Tohoku University (in Japanese with English abstract). 
Shibata, TORU

1995 Lithic raw materials in south Kanto Region, in Third Iwajyuku Forum/Symposium. Lithic Raw Materials: 50-53, ed. The Iwajyuku Forum Executive. Kasagakeno: Kasagakeno Iwajyuku Museum (in Japanese).

Tamura, Takashi, and Sadakatsu Kunitake

2006 New discoveries of lithic resources in the north of the "Shimotsuke-Hokuso Corridor" (3). Chiba Kenshi Kenkyu 14:137-1128 (in Japanese).

Tamura, Takashi, Sadakatsu Kunitake, and Masayuki Yoshino

2003 New discoveries of lithic resources in the north of the "Shimotsuke-Hokuso Corridor" (1). Chiba Kenshi Kenkyu 11:153-143 (in Japanese).

2004 New discoveries of lithic resources in the north of the "Shimotsuke-Hokuso Corridor" (2). Chiba Kenshi Kenkyu 12:96-83 (in Japanese).

\begin{abstract}
During the Terminal Pleistocene in central Honshu, which coincided temporally with the emergence of pottery, lithic raw material reduction sequences ceased to be rational and economical, instead becoming expedient and wasteful. Furthermore, huntergatherers had stopped importing lithic raw materials over long distances, and attempts made previously to attain a maximum number of usable edges on artifacts upon one nodule had ceased. Their reduction sequences might have no longer required a sparing strategy, since they now used abundant local raw materials, probably due to reduced mobility. It is suggested that the emergence of pottery allowed them to exploit more diverse plant sources and enabled them to survive within smaller territories, while the lithic reduction strategies changed as they adapted to use of available lithic raw materials. KeYwORDS: Japan, Honshu, microblades, bifacial points, lithic economy, mobility, foragers.
\end{abstract}

